University of Nebraska - Lincoln

DigitalCommons@University of Nebraska - Lincoln

Management Department Faculty Publications

Management Department

\title{
$5-2011$
}

\section{Aligning strategic processes in pursuit of firm growth}

Varkey K. Titus Jr.

University of Nebraska-Lincoln, vtitusjr2@unl.edu

Jeffrey G. Covin

Indiana University, covin@indiana.edu

Dennis P. Slevin

University of Pittsburgh, dpslevin@katz.pitt.edu

Follow this and additional works at: https://digitalcommons.unl.edu/managementfacpub

Titus, Varkey K. Jr.; Covin, Jeffrey G.; and Slevin, Dennis P., "Aligning strategic processes in pursuit of firm growth" (2011). Management Department Faculty Publications. 97.

https://digitalcommons.unl.edu/managementfacpub/97

This Article is brought to you for free and open access by the Management Department at DigitalCommons@University of Nebraska - Lincoln. It has been accepted for inclusion in Management Department Faculty Publications by an authorized administrator of DigitalCommons@University of Nebraska - Lincoln. 


\title{
Aligning strategic processes in pursuit of firm growth
}

\author{
Varkey K. Titus Jr., ${ }^{1}$ Jeffrey G. Covin, ${ }^{1}$ and Dennis P. Slevin ${ }^{2}$ \\ 1. Indiana University, Kelley School of Business, Bloomington, IN 47405, USA \\ 2. University of Pittsburgh, Katz Graduate School of Business, Pittsburgh, PA 15260, USA \\ Corresponding author - V. Titus, current address: College of Business Administration, University of Nebraska-Lincoln \\ Emails: covin@indiana.edu (J. G. Covin), dpslevin@katz.pitt.edu (D. P. Slevin), vtitusjr2@unl.edu (V. K. Titus)
}

\begin{abstract}
Strategy formation mode refers to the way organizations devise their strategies. While some organizations do so through an explicit, formalized, and planned method, other organizations unintentionally create patterns in their strategic decisions a strategy formation route that is more emergent in nature. This research explores the relationship between strategy formation mode and firm growth. Further, this article explores two strategic processes - forecasting and long-range objective setting - and their efficacy in association with particular strategy formation modes. Primary and secondary data collected from 103 manufacturing firms were used to test the hypotheses. Results indicate that the relationship between strategy formation mode and firm growth is curvilinear (inverted-U shape). Further, a three-way interactive effect is found between strategy formation mode, forecasting, and long-range objective setting on firm growth.
\end{abstract}

Keywords: Strategy formation, Growth, Forecasting, Objective setting

\section{Introduction}

Strategy formation can be an intentional and deliberate process wherein organizations create future-oriented plans that are aimed at exploiting opportunities in accordance with the mission of the organization (Newman and Logan, 1981: 7). Strategy formation can also occur in a less formalized way. Mintzberg and Waters (1985) conceptualize strategy formation as falling on a spectrum, where one extreme is purely emergent and the other extreme is purely planned. A purely emergent strategy is defined as one where there is "order-consistency in action over time-in the absence of intention about it"; a purely planned strategy must meet three requirements: explicit articulation of intention, the commonality of intentions amongst actors, and intentions carried out exactly as planned (Mintzberg and Waters, 1985). Organizations rarely utilize these pure forms of strategy formation; rather, most strategies lie somewhere between these extremes on the strategy formation continuum. Moreover, according to Mintzberg (1994: 111), "all viable strategies have emergent and deliberate [i.e., planned] qualities."

Planned strategies have been extensively studied. Research has examined the antecedents to planning (Harris and Ogbonna, 2006) as well as planning's relationship to firm performance (Miller and Cardinal, 1994). Studies exploring the relationship between planning and performance have produced conflicting results. For example, Miller and Cardinal (1994) find a positive relationship in their overview of the literature, while Greenley (1994) posit that no such conclusion about this relationship can be established from his review of 29 studies. Boyd (1991) conducted a meta-analysis of 29 studies, and though he found a modest positive relationship, he notes that there are numerous measurement errors in the studies, making them generally unreliable.

Recently, emergent strategies-including those that entail emergent qualities but are not explicitly labeled "emergent" (e.g., flexible strategies) - have received increased attention and advocacy (Dreyer \& Grønhaug, 2004; Shimizu \& Hitt, 2004). Unlike research on planned strategies, few studies to date have explored the performance effects associated with more emergent strategies (for exceptions, see Dreyer \& Grønhaug, 2004; Rudd et al., 2008). Rarer still are studies that examine the performance effects of strategy formation mode when emergent and planned strategies are recognized as two ends of a continuum (for exceptions, see Harrington et al., 2004; Slevin \& Covin, 1997).

The purpose of the current research is to contribute to the scholarly conversation regarding the relationship between strategy formation mode and firm performance by modeling this relationship in manners consistent with Mintzberg's (1994) observations that (1) emergent and planned strategy formation modes are two ends of a strategy formation continuum and (2) all viable strategies have emergent and planned qualities. The departure here from past research is that prior research has sought to find a main effect on firm performance for either planned strategies or, to a lesser extent, emergent strategies. This either-or characterization does not align with Mintzberg's (1994) observations on the manner in which strategy is manifest in organizations. Moreover, assuming that Mintzberg (1994: 111) is correct that "all viable strategies have emergent and deliberate [i.e., planned] qualities," prior research focused solely on the performance effects of either planned or emer- 


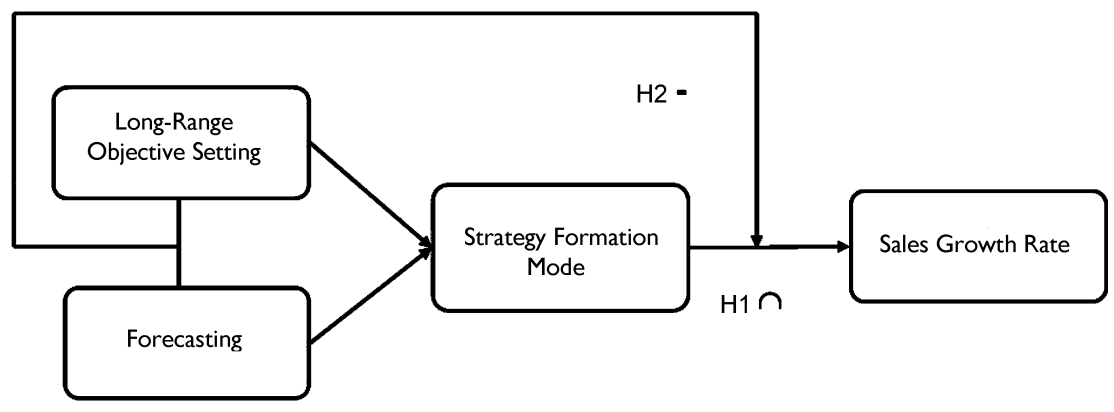

Figure 1. Research model.

gent strategies will not have captured the strategy formation quality argued by Mintzberg (1994) to be most strongly associated with firm success - that is, the concurrent exhibition of planned and emergent strategic elements.

\section{Theoretical development and hypotheses}

\subsection{The research model}

The research model for this study is shown in Figure 1. Firm growth, represented by sales growth rate, is the dependent variable of this study for several reasons. First, sales growth rate is a commonly used performance measure in the planning literature (Boyd, 1991). The frequent adoption of this variable as a desirable performance metric is attributable to the facts that (1) growth is an indicator of the effectiveness with which firms exploit current or new product-market opportunities and (2) growth is a recognized generator of organizational slack, which can buffer firms against environmental shocks and, thereby, contribute to sustained organizational viability (see Shepherd and Wiklund, 2009). Moreover, growth-related measures tend to be more readily available and reliable than performance measures focused on efficiency concerns, such as ROA (He and Wong, 2004). This last point is an important consideration when secondary data are to be used to corroborate primary data, as was the researchers' intent in the current study.

The independent variable in this study is strategy formation mode, conceptualized as Mintzberg conceived it-strategy formation mode exists on a continuum where one end is purely emergent and the other end is purely planned. There are two moderating variables proposed in this study: long-range objective setting (LROS) and forecasting. LROS refers to organizations creating goals and objectives to achieve in the future, and forecasting refers to predicting market, competitive, and environmental changes and trends. Because previous theorizing suggests that both LROS and forecasting can operate as antecedents to a planning orientation (e.g., Bracker and Pearson, 1986), the research model reflects this likelihood. However, because the principal focus of this article relates to strategy formation mode and the strategic processes that may facilitate or attenuate its effectiveness, the possible main effects of LROS and forecasting on strategy formation mode are not hypothesized.

Emergent strategies have been recognized in recent years as a normative state (Shimizu and Hitt, 2004) - a recognition that planned strategies once had (Mintzberg, 1994). However, emergent strategies can be potentially hazardous as they may make firms subject to strategic drift or noncumulative strategic opportunism (Idenburg, 1993). As Slevin and Covin (1997: 202) state, "...arguments that one strategy formation approach is inherently (emphasis added) superior to the other...appear moot." In that article, Slevin and Covin study the impact that the external environment and firm structure have on the strategy formation mode-firm performance relationship. Con- trary to previous theoretical assumptions, the authors propose (and find) that planned strategies are more positively related to firm performance in hostile environments, and when the firm has a mechanistic structure. Conversely, emergent strategies tended to be more positively related to firm performance in benign environments, and when the organization has an organic structure. The authors argue that, in hostile environments, poor decisions may have dire consequences, while firms in benign environments may benefit from a "learn as you go" orientation, as any given strategic misstep would not likely produce unforgiving results.

While the environment is an important contingency factor in strategy formation mode research, it is not the focus of the current research. Instead, this paper explores the strategic processes that facilitate success among firms with variously emergent/planned strategies across environmental settings (after controlling for environmental effects). It is suggested here that LROS and forecasting are two strategic processes that can moderate the effectiveness of particular strategy formation modes. Long-range objectives represent beacons toward which an organization can navigate. The utility of such objectives rests on their accuracy; stated differently, uninformed objectives could prove detrimental, rather than beneficial, to firm growth. It is argued here that forecasting future changes and trends can help the firm create viable long-range objectives, which may be especially beneficial to firms that exhibit particular strategy formation modes.

\subsection{Strategy formation mode and firm growth}

Slevin and Covin (1997) drew a conceptual link between emergent and planned strategy and rationality in strategic decision making processes, where planned strategies reflect decisions in the rational mode and emergent strategies reflect bounded rationality. The concept of bounded rationality - and how it applies to emergent strategy - is further illustrated by Mintzberg: "Smart strategists appreciate that they cannot always be smart enough to think through everything in advance" (1987: 69). This does not imply that planned strategies are created with full rationality; instead, for a purely planned strategy to be realized as intended, there must be knowledge and control of exactly how the strategy will interact with other forces within and outside of the organization (Mintzberg and Waters, 1985). An additional conceptual link can be drawn between emergent strategy and strategic flexibility, which can be defined as the ability to identify major changes in the environment, to commit new resources in response to change, and to halt and reverse potentially unproductive commitments (Shimizu and Hitt, 2004). Emergent strategies emphasize the ability to adapt and "change course" when needed (Covin, Green, and Slevin, 2006).

Research in the strategy formation literature includes other factors that differentiate strategy formation processes. For ex- 
ample, Harrington (2005) includes an individualistic/collectivistic dimension, where "individualistic" refers to only the CEO or top executives participating in the strategy making process, whereas "collectivistic" refers to broad involvement throughout the hierarchy. In his study of major oil companies, Grant (2003) proposes the concept of "planned emergence," where planning occurs "bottom-up" (considered an emergent quality), while corporate management creates and maintains a system of constraints and guidelines via mission statements, performance expectations, and corporate initiatives (considered a planned quality). While Grant's (2003) work examines decision-making structure as an indication of emergent or planned qualities, the current paper focuses on the extent to which firm strategies are planned in advance of actions taken as a defining quality of the strategy formation process. Thus, while there are similarities between the current research and that of Harrington and Grant, this paper offers a unique contribution by focusing on the level of strategic decision predetermination in the strategy formation process itself, rather than the decision-making structures utilized by the organization.

The critiques of formal, planned strategy are well articulated and plentiful. One of the main criticisms for planned strategy is that it is conducive to rigidity, and can therefore prevent organizations from exploring innovations not a part of the plan (Miller and Cardinal, 1994). Explicitly planned strategies can act as "blinders designed to focus direction and block out peripheral vision" (Mintzberg, 1990: 184). Planned strategies that do not leave room for adaptability may not be able to exploit underestimated opportunities because resources are committed elsewherenamely, to overestimated opportunities (Covin et al., 2006).

Further, an operational precept of purely planned strategies is that accurate forecasts can be made, an assumption that denies the reality of uncertainty. According to Mintzberg, "While certain repetitive patterns, such as seasons, may be predictable, the forecasting of discontinuities...is virtually impossible" (1994: 110). Uncertainty is, by definition, not something that can be accurately planned for with confidence. Assuming knowledge of the unknown is "...the perfect way to sail straight into an iceberg" (Mintzberg, 1987: 26). Another danger of forming explicit plans involves the psychological effect it has on the planners. Specifically, decision-making that underestimates the level of uncertainty the organization faces could lead to overconfidence in judgment (Hogarth, 1975), as well as engender a superficial and false sense of understanding (Mintzberg, 1990). Lastly, carefully-devised plans will produce superior performance only if a firm is able to successfully implement the plan (Noble, 1999). However, given the aforementioned considerations of uncertainty, it is likely that plan modification will be necessary to assure firm success.

The disadvantages of planned strategies can serve as bases of advantage for emergent strategies. Emergent strategies are conducive to flexibility and adaptability, which can enable firms to reallocate resources mid-stream from opportunities with little promise to those with greater promise, allowing firms to act more innovatively (Tuominen, Rajala, and Möller, 2004). Organizations that utilize emergent strategy formation modes benefit from the acquisition and utilization of real-time knowledge that can help them respond to changing environmental and organizational demands (Covin et al., 2006). For organizations that actively seek to innovate, an emergent strategy formation mode can be critical: “...emergent strategies can enable entrepreneurial firms to retain the strategic flexibility they need to successfully operate under conditions where the most defensible strategic paths are not easily knowable yet significant losses and opportunity costs may be incurred if the wrong strategic path is chosen" (Covin et al., 2006: 62). As demonstrated above, the virtues of emergent strategiesflexibility and adaptability - have been extolled extensively in previous literature. Nonetheless, organizations that utilize purely emergent strategy formation modes may find themselves being too reactive and ad hoc in their actions. Purely emergent strategy may lead to haphazard guess work that creates misalignment between the organization and the environment (Armstrong, 1982).

In short, unique liabilities are associated with both emergent and planned strategies. As indicated by Mintzberg (1994), neither purely emergent nor purely planned strategies will maximize firm performance. Instead, every viable strategy should have some degree of both modes: “...all must combine some degree of flexible learning with some degree of cerebral control" (Mintzberg, 1994: 111). It is with this in mind that the first hypothesis is proposed:

H1. The relationship between strategy formation mode and sales growth rate is curvilinear (inverse U-shaped) such that sales growth rate is highest at a midpoint on the emergent-to-planned strategy formation mode continuum.

\subsection{The joint interaction of forecasting and long-range objective-setting on the strategy formation mode-firm growth relationship}

As previously mentioned, this research explores the strategic processes that facilitate the success of particular strategy formation modes. Two strategic processes are investigated here: forecasting and long-range objective setting (LROS). In this study, forecasting is defined as the process through which market, competitive, and environmental changes and trends are predicted. LROS is defined as the process through which explicit objectives or goals are set for the organization. These two strategic processes were chosen for examination for two principal reasons. First, along with strategy formation mode, forecasting and LROS constitute core aspects of the means through which purpose and direction are established by organizations. As such, some of the most important elements of what strategic management practice "looks like" in organizations can be revealed via examination of these three strategic variables. Second, and as detailed more specifically below, forecasting and LROS are expected to interrelate with strategy formation mode such that the efficacy of particular strategy formation processes will be contingent upon how or how well the other processes are executed. For example, forecasting can used to establish or verify the appropriateness of strategic objectives, and the presence of empirically-informed strategic objectives may, in turn, have various utility among firms that employ different strategy formation modes.

The first strategic process examined in this study is LROS, which is operationalized as the setting of explicit future objectives concerning the firm's capital budgets, finances, and market development. This operationalization does not include identification of the means through which the organization accomplishes those objectives. The setting of long-range objectives establishes, in essence, the beacons toward which organizations sail. An emergent strategy formation mode allows the firm to adaptively and flexibly sail towards the beacon; obstacles - or opportunities - that arise along the way can be evaded or pursued to increase the likelihood of attaining the objective. Conversely, if the organization utilizes a planned strategy to arrive at the goal - that is, the organization sets the objective and then explicitly plots a course toward the beacon-the set path may prove perilous, but the lack of flexibility and adaptability may cause the organization to stay on course and sail "straight into an iceberg" (Mintzberg, 1987: 26). The current research does not examine the influence of LROS alone on the strategy formation mode-firm growth relationship. Instead, a second strategic process, forecasting, is examined concurrently with LROS, as it will be argued that forecasting can help inform the creation of viable objectives.

Organizations can engage in forecasting in an attempt to better understand how to adapt to a continually evolving competitive environment. Generally, forecasting is used to understand how a particular set of circumstances will affect the 
organization. Central to the concept of forecasting is the argument that firm performance is affected by an organization's ability to anticipate environmental changes and allocate resources accordingly. However, forecasting should not be viewed as an invariably useful activity. Organizations that engage in forecasting are susceptible to biases that could lead to inaccurate predictions and, therefore, lower performance. For example, Durand (2003) discusses two potential causes of forecasting bias: the illusion of control and attention issues.

The illusion of control bias has significant implications for organizations, particularly those utilizing planned strategies. This bias concerns the positive misconception of control-the belief that an entity has control when it does not-and leads to the inaccurate assessment of risks. The greater the perception of control over a given event, the greater the probability of underestimating the risks involved with that event (Durand, 2003). Organizations pursuing emergent strategies may be less likely to fall prey to illusions of control. Indeed, emergent strategies are sensitive to the idea that the organization cannot control the future and therefore must approach it flexibly. On the other hand, organizations that utilize highly planned strategies may be particularly susceptible to perceiving a greater amount of control over the environment than they actually have.

Attention issues are the other source of bias Durand (2003) discusses. This bias relates to where organizations invest their attention when engaging in forecasting activities - toward internal or external matters. According to Durand (2003), forecasting will be most beneficial for those firms that invest more heavily in externally-oriented information (e.g., market research) than internally-oriented information (e.g., employee education). It should be noted here that this article's usage of the forecasting construct focuses on external information.

Earlier in this article, Mintzberg (1994) was quoted regarding his view on forecasting. Specifically, he states that the forecasting of "discontinuities...is virtually impossible" (1994: 110). The context of his argument deals with the fallacy of assuming that the world will "hold still" during the planning process, and then formulating plans based on these staticworld assumptions. The argument proposed in this article is that, for firms that utilize emergent strategies, there is greater sensitivity to the dynamic nature of the environment. As such, there is a lower probability of the firm succumbing to the "fallacy of prediction" discussed by Mintzberg (1994).

It is herein argued that when LROS and forecasting are used in concert they will modify the relationship between strategy formation mode and firm growth most strongly. Specifically, among firms that actively engage in forecasting, long-range objectives will be empirically-informed and viable. Forecasting, therefore, serves the function of informing the creation of viable objectives. In such circumstances, the adaptability of an emergent strategy formation mode will prove beneficial to the firm, as forecasting and LROS imbue a form of "cerebral control," while the emergent strategy formation mode will allow for adaptive learning. Stated differently, organizations that create goals and objectives based on forecasts that anticipate environmental and competitive changes and trends are more likely to create viable, attainable goals than those organizations that do not engage in such forecasting. To continue the allegorical imagery used in this article, forecasting can be conceptualized as a process utilized to help create viable beacons. Organizations that sail toward these beacons should do so adaptively, as the best path toward the beacon may not be clear until the journey is underway. The following hypothesis is proposed:

H2a. Among firms that actively engage in forecasting, an emergent (planned) strategy formation mode is more positively (negatively) related to sales growth rate when the firm prepares explicit long-range objectives than when they do not.

Conversely, among firms that do not actively engage in forecasting, emergent strategy will not be as positively related to firm growth when LROS is practiced. This is because objectives that are created without being informed by forecasts may prove inaccurate; in such a case, these objectives may be detrimental to firms, and there will be a lack of needed direction in the organization's strategic maneuvers. The absence of forecasting will result in potentially misinformed objectives that can lead firms with emergent strategies to falter. Significantly, among firms with planned strategies the need for emphasizing both forecasting and LROS may not be as great nor as strong a determinant of firm growth because the joint exhibition of forecasting and LROS may suggest that the illusion of control bias (Durand, 2003) is operating among these firms. Moreover, consistent with Mintzberg's (1994) observation that a planning orientation can diminish firm adaptability, the joint exhibition of forecasting and LROS among planned strategy firms can crystallize commitment to predetermined courses of action and diminish receptiveness to environmental feedback which conflicts with a priori assumptions. The following hypothesis is proposed:

H2b. Among firms that do not actively engage in forecasting, an emergent (planned) strategy formation mode is more positively (negatively) related to sales growth rate when the firms do not prepare explicit long-range objectives than when they do.

\section{Methods}

\subsection{Sample and data collection}

Data were collected in cooperation with and under the partial sponsorship of the Southwestern Pennsylvania Industrial Resource Center - a regional economic development organization. A total of 418 firms were selected utilizing this organization's census of businesses in the Pennsylvania, Ohio, and West Virginia region, using the criteria that they be nondiversified business units that are manufacturing based and have 50 or more employees. Diversified firms were excluded from the sample because they might employ different strategic processes across their product lines or business units, which would confound results. By focusing on manufacturing-based organizations, the study controlled for macro-industry effects through the elimination of multiple and diverse industry sectors from the sample. Finally, by selecting only firms with 50 or more employees, predictable size-related biases on the research variables were avoided (e.g., smaller firms characteristically exhibit more emergent strategy-formation patterns; Mintzberg, 1973).

Two questionnaires were mailed to the senior-most executive, considered the primary respondent, of each of the 418 firms selected for the study as described above. This individual was asked to complete a questionnaire personally as well as to refer the second questionnaire to another senior executive who would serve as a secondary respondent. The second individual was to be selected on the basis of that individual's overall understanding of the business and level of involvement in the firm's strategic processes. The secondary respondents' data were used solely for measure corroboration and reliability purposes.

This research drew an organizational response rate of $27.5 \%$ (115 responses from the 418 selected firms), with usable responses being received from 115 primary respondents and 55 secondary respondents. This study utilized information from 103 of these firms, as only these firms had complete data available on all of the study's measures. The diversity of this final sample is reflected in the 74 different 4-digit standard industrial classification (SIC) codes among the 103 firms, with no identical SIC code being represented by more than six firms. Sixty-four of the 103 firms were privately owned, while 39 were publicly owned. The average sales revenue and age of the firms in the sample were $\$ 132.3$ million (SD $=\$ 435.73$ million) and 47.6 years ( $S D=30.70$ years), and the average number of employees among these firms was 793.8 (SD =2,447.13). 
$t$-test comparisons of the average size (computed by both number of employees and annual sales) and age of the responding firms with the same data for non-responding firms (where available from secondary sources such as Ward's Business Directory of U.S. Private and Public Companies) showed no significant differences $(p>.10)$ between the two groups. $t$ test comparisons of early respondents (those firms that returned the questionnaires without second contact) and the late respondents (those who replied after the second telephone contact) also revealed no significant differences between the two groups in number of employees, annual sales revenue, firm age, or any of the other research variables of interest to this study. In all cases, the $t$-value was less than $1.50(p>.10)$.

\subsection{Measures}

\subsubsection{Sales growth rate}

Firm performance was measured as a firm's sales growth rate relative to its industry, and was operationalized as the firm's average rate of growth in sales revenue over its most recent 3 -year period. In those cases where secondary sales revenue data were available ( 25 of the firms), the primary and secondary numbers matched each other or were rounded approximations of each other. The correlation between the firms' actual, year-to-year sales figures and the self-reported three-year average sales growth rates was $r=.85$. To account for differing growth rates in the industries represented in the sample, the 3-year average industry growth rate for each firm was subtracted from the firm's 3-year average growth rate. This created an industry-controlled relative sales growth rate figure which was used as the dependent variable.

\subsubsection{Strategy formation mode}

Slevin and Covin's (1997) 5-item, 7-point scale was used to measure the construct of strategy formation mode. A low score on this scale indicates an emergent strategy pattern, while a higher score indicates a planned or intended strategy orientation.

\subsubsection{Forecasting}

This construct was measured using a 3-item, 7-point scale developed for this study. The items in this scale assessed how actively the organization engages in the forecasting of market, competitive, and general environmental changes and trends. A high score on this scale indicates that the firm actively engages in forecasting activities.

\subsubsection{Long-range objective setting}

This construct was measured using a 3-item, 7-point scale developed for this study. The items in this scale assessed degree of emphasis placed on the development of explicit, long-term (3 years or more) financial, market development, and capital budget objectives. A high score on this scale indicates greater emphasis on LROS.

\subsubsection{Control variables}

Firm size and age were controlled because of the expectation that the strategic processes of interest might vary systematically with these variables (e.g., Mintzberg, 1973). Firm size was assessed as the number of employees, and firm age was assessed as the number of years the firm had been in business. Environmental dynamism and hostility were treated as control variables due to the recognition that the environment has been found to influence the efficacy of particular strategy formation patterns (e.g., Miller and Cardinal, 1994). Dynamism was measured using a slightly modified version of Miller and Friesen's (1982) 5-item, 7-point scale. Higher scores reflected more dynamic environments. Hostility was measured using Slevin and Covin's (1997) 6-item, 7-point scale. Higher scores reflected more hostile environments. Finally, due to the recognition that strategy takes time to manifest (Brews and Hunt,
1999), dummy variables were added that address change in strategic management practices over the last three years in regards to (1) "futurity" - how far into the future top-level managers look to anticipate market conditions and (2) "time involvement" - the amount of time top managers spend analyzing key operating and strategic decisions. These variables were measured on a 7-point scale in which 4 represents "no change" over the last three years. The absolute value of the deviation from a response representing "no change" was used as the change score for the variables. These change scores were treated as controls in the analyses, the assumption being that firms that have changed their futurity or time involvement may be executing the specific strategic processes observed in the current study differently at the time of the data collection relative to three years prior, thereby undermining the causal chain on which the current research model is based.

\subsection{Analytical techniques and tests for common method bias}

The hypotheses in this study were tested using hierarchical regression analysis, as recommended by Arnold (1982). Natural logs were used for firm size and age in order to normalize the distribution of these variables as they were somewhat skewed. To minimize correlations between the independent variables and their interaction terms, the independent variables were centered as recommended by Aiken and West (1991) prior to the computations involving the interaction terms. Variance inflation factors (VIFs) were computed for all independent variables, including the interaction terms, in the regression equations. The highest VIF was 3.33, within the accepted range of 10 (Hair, Anderson, Tatham, and Black, 1998), indicating that multicollinearity is not a problem in the current analyses.

To check for the presence of possible common method bias in the results, a technique described by Podsakoff et al. (2003) was utilized. This technique tests the effect of a latent methods factor, which captures common methods variance, on the correlations among the research variables. The result of this analysis suggested that common methods effects, if present, do not materially impact the findings of the current research.

\section{Results}

Table 1 shows the summary statistics and correlation matrix for the measures used. The research model shown in Figure 1 indicates that LROS and forecasting may operate as antecedents to strategy formation mode. Although these specific relationships were not formally hypothesized, a regression analysis was conducted which revealed that LROS and forecasting are, in fact, significantly (at the $p<.001$ and $p<.01$ levels, respectively) and positively associated with strategy formation mode.

Table 2 presents the regression results. The significant $(p<.05)$ and negative beta for the strategy formation mode squared term shown in Model 2 is consistent with Hypothesis 1; it indicates a curvilinear relationship between strategy formation mode and sales growth. The negative beta indicates that the relationship looks like an inverted U, denoting that optimal sales growth occurs at a middle point on the strategy formation mode scale.

In Model 4 , the negative and significant $(p<.01)$ beta for the three-way interaction term supports Hypothesis 2 (i.e., both $2 \mathrm{a}$ and $2 \mathrm{~b}$ ). The graphical representations for the threeway interaction are shown in Figure 2A and B. The three-way interaction plots were created by splitting the sample by those organizations that engage in a "high" or "low" degree of forecasting. Figure 2A illustrates the interaction effect on sales growth of strategy formation mode and LROS in organizations that actively engage in forecasting. Consistent with $\mathrm{Hy}-$ pothesis $2 \mathrm{a}$, among firms that actively engage in forecasting, emergent (planned) strategies have a more positive (negative) relationship with sales growth rate when LROS is emphasized. Consistent with Hypothesis 2b, Figure 2B shows that 
Table 1. Summary statistics and correlation matrix $(N=103)$.

\begin{tabular}{|c|c|c|c|c|c|c|c|c|c|c|c|c|}
\hline Variable & Mean & s.d. & $a$ & 1 & 2 & 3 & 4 & 5 & 6 & 7 & 8 & 9 \\
\hline 1. Sales growth rate & -1.1 & 14.73 & n.a. & & & & & & & & & \\
\hline 2. Firm size & 793.8 & 2447.13 & n.a. & 0.13 & & & & & & & & \\
\hline 3. Firm age & 47.6 & 30.70 & n.a. & -0.08 & $0.21^{*}$ & & & & & & & \\
\hline 5. Env. hostility & 4.3 & 0.96 & 0.67 & -0.06 & -0.18 & -0.14 & 0.18 & & & & & \\
\hline 6. Change in futurity & 4.2 & 1.29 & n.a. & 0.10 & -0.13 & $0.21^{*}$ & -0.12 & $-0.31^{* *}$ & & & & \\
\hline 7. Change in time involvement & 4.9 & 1.16 & n.a. & -0.16 & 0.06 & 0.07 & -0.02 & -0.06 & $0.46^{* *}$ & & & \\
\hline 8. Strategy formation mode & 4.1 & 1.34 & 0.89 & 0.07 & $0.34^{\star *}$ & 0.12 & 0.18 & -0.01 & $0.31^{* *}$ & $0.28^{* *}$ & & \\
\hline
\end{tabular}

${ }^{*} p<.05 ;{ }^{* *} p<.01$

for firms that do not actively engage in forecasting, emergent (planned) strategies are more positively (negatively) related to sales growth rate when LROS is not emphasized.

\section{Discussion and Conclusion}

There are two primary theoretical implications of this study. First, this study suggests that, consistent with Mintzberg's (1994) observations on effective strategy formation processes, neither purely emergent nor purely planned strategies should be regarded as inherently desirable. Rather, the optimal amount of planning orientation, as exhibited on an emergent-to-planned strategy continuum, likely occurs at some midpoint on that continuum. The observed curvilinear relationship between strategy formation mode and firm growth rate indicates that growth is highest when the firm's strategy exhibits both emergent and planned qualities. While this empirical finding is consistent with prior theorizing, no prior research has empirically tested for the aforementioned curvilinear relationship. The significance of this finding becomes apparent when one considers the strong advocacy often seen in the popular business press of strategic management approaches that embrace flexibility and adaptability over planning (e.g., D'Aveni and Gunther, 1994). This "new" approach to strategic management is no more enlightened than the traditional planning approaches commonly extolled in the classic business planning literature (e.g., Andrews, 1971; Ansoff, 1965). Future theorists may be well advised to refrain from framing their ideas about effective strategy formation processes as involving an emergent strategy orientation or a planned strategy orientation and, instead, recognize the centrality to firm success of having both orientations.

A second theoretical implication of this research is that the way in which the strategy formation process is paired with other strategic processes-namely, forecasting and LROScan have significant performance-related effects for firms. It was previously argued that forecasting can empirically inform the creation of viable long-range objectives, which can then be set as beacons toward which the firm navigates. Nonetheless, the current findings suggest that the utility of concurrently stressing forecasting and LROS is greater among firms with emergent than planned strategy orientations. Among firms with emergent strategies, the exhibition of forecasting and LROS may create a needed and informed sense of purpose that leads the firm in empirically defensible directions. However, forecasting may not as strongly influence the efficacy of LROS among firms with planned strategies, because such firms may be less likely to question the veracity of objectives whose establishment has been empirically informed through forecasting. The empirical defensibility of pairing formal forecasting and objective setting among firms with a planning orientation may result from and contribute to a deterministic mindset in which the firm believes it has more control over its destiny than it actually does. In other words, a concurrent em- phasis on forecasting, LROS, and planned strategies may be a perfect recipe for creating the aforementioned illusion of control bias (Durand, 2003). Consequently, firms that employ this mixture of strategic processes may be reluctant to ever deviate from their plans, even when such deviation is warranted.

There are two primary managerial implications of this research. First, neither strategy formation mode is the inherently superior path to creating effective strategy. Purely emergent strategies can lead to reactive, overly ad hoc, and non-purposeful strategies. Though flexibility is an often-lauded strategic virtue, it can prove unbeneficial to organizations. Indeed, if an organization changes course too frequently, or changes course for the sake of change alone, there will be undesirable consequences (Parnell, 1994). Likewise, a strong planning orientation, particularly when paired with empirical evidence that prior objectives were established based on the best available data, may contribute to a false sense of control and, perhaps, an unwillingness or inability to learn from past strategic missteps (Mintzberg, 1990).

Table 2. Regression results.

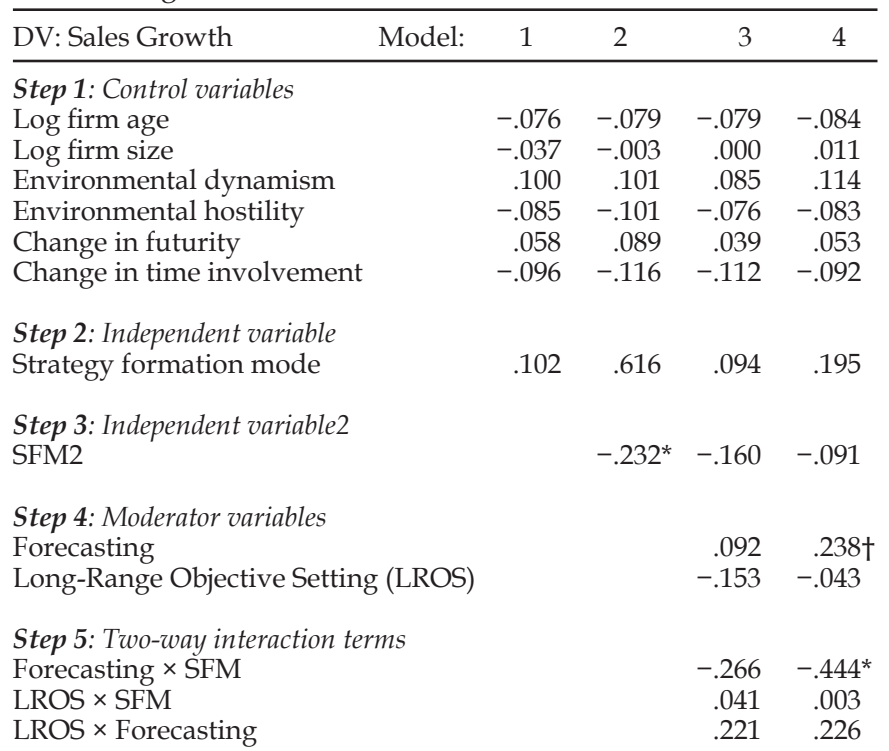

Step 6: Three-way interaction

LROS $\times$ Forecasting $\times$ SFM

$-.491^{* *}$

Model R2

Change in $R 2$

$\begin{array}{llll}.031 & .081 & .129 & .216\end{array}$

Model F

$\begin{array}{llll}.432 & 1.045 & 1.011 & 1.728 \dagger\end{array}$

Standardized regression coefficients are reported $\dagger p<.10 ;{ }^{*} p<.05 ;{ }^{* *} p<.01 ; N=103$ 

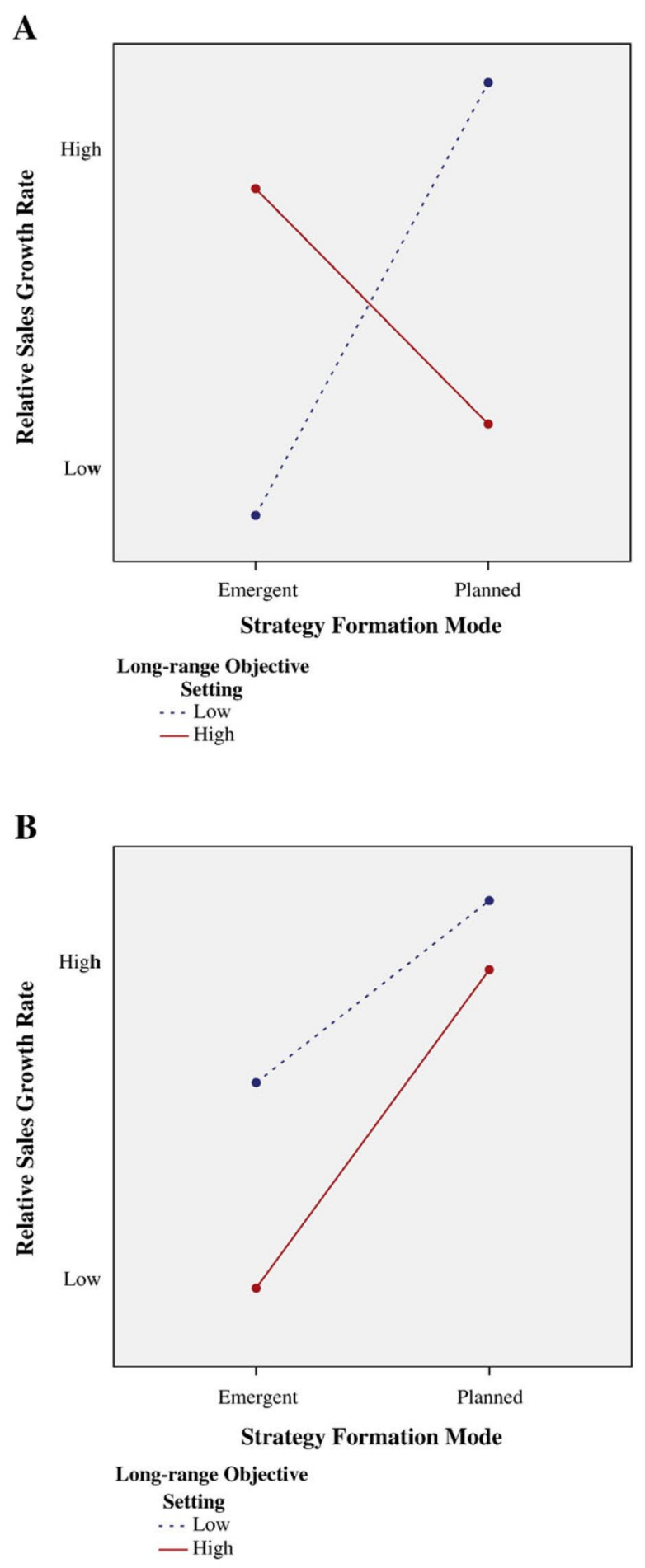

Figure 2. a) High forecasting. b) Low forecasting.

The second managerial implication of this research is that executives should be amenable to allowing their firms' strategies to evolve, but only when those firms exhibit purposeful strategic behavior that directs the firm toward well-considered ends. Stated differently, strategic flexibility must be recognized as a complement to-not a substitute for-clear directionality and purposefulness vis-à-vis empirically-derived objectives. The presence of such objectives can help insure that strategies unfold in manners that best enable the firm to incre- mentally navigate toward strategic positions explicitly recognized as desirable. In short, prior research suggests that strategic planning should be tempered with operational flexibility in order to promote firm performance (Rudd et al., 2008). This research offers the complementary perspective that emergent strategies may best promote performance when they unfold in the presence of explicit, empirically-derived objectives.

In conclusion, the increasingly dynamic nature of the modern competitive environment necessitates close examination of the strategic processes through which organizations can succeed. Work in both the popular press and more scientific literature tends to propose that control is had at the expense of adaptability, or adaptability at the expense of control. This article seeks to challenge this assumption by exploring how certain strategic processes may be utilized to imbue control in emergent strategies and, conversely, how these same processes may impede the effectiveness of planned strategies. Though forecasting and long-range objective setting may prevent some firms from succumbing to strategic drift and nonpurposefulness, they may cause other firms to put greater faith into the appropriateness of their strategic actions than is warranted, prompting strategic rigidity. Firms that learn how to effectively adapt without losing focus, to sail the trade winds without becoming lost, will most successfully navigate tumultuous waters.

Acknowledgements - The authors wish to thank Journal of Business Research editor Mario Krenn as well as the two anonymous reviewers for their many helpful comments and suggestions throughout the review process.

\section{References}

Aiken LS, West SG. Multiple regression: testing and interpreting interactions. Sage Publications Inc.; 1991.

Andrews KR. The concept of corporate strategy. Homewood, IL: Irwin; 1971.

Ansoff HI. Corporate strategy: an analytic approach to business policy for growth and expansion. New York: McGraw-Hill; 1965.

Armstrong JS. The value of formal planning for strategic decisions: review of empirical research. Strateg Manage J 1982;3(3):197-211.

Arnold HJ. Moderator variables: a clarification of conceptual, analytic, and psychometric issues. Organ Behav Hum Perform 1982;29(2):143-74.

Boyd BK. Strategic planning and financial performance: a metaanalytic review. J Manage Stud 1991;28(4):353-74.

Bracker JS, Pearson JN. Planning and financial performance of small, mature firms. Strategic Strateg Manage 1986;7(6):503-22.

Brews PJ, Hunt MR. Learning to plan and planning to learn: resolving the planning school/learning school debate. Strateg Manage J 1999;20(10):889-913.

Covin JG, Green KM, Slevin DP. Strategic process effects on the entrepreneurial orientation-sales growth rate relationship. Entrep Theory and Pract 2006;30(1):57.

D'Aveni RA, Gunther RE. Hypercompetition: managing the dynamics of strategic maneuvering. New York: The Free Press; 1994.

Dreyer B, Grønhaug K. Uncertainty, flexibility, and sustained competitive advantage. J Bus Res 2004;57(5):484-94.

Durand R. Predicting a firm's forecasting ability: the roles of organizational illusion of control and organizational attention. Strateg Manage J 2003;24(9):821-38.

Grant RM. Strategic planning in a turbulent environment: evidence from the oil majors. Strateg Manage J 2003;24(6):491-517. 
Greenley GE. Strategic planning and company performance: an appraisal of the empirical evidence. Scand J Manage 1994;10(4):383-96.

Hair JF, Anderson RE, Tatham RL, Black WC. Multivariate data analysis. Upper Saddle River, NJ: Prentice-Hall, Inc.; 1998.

Harrington RJ. The how and who of strategy making: models and appropriateness for firms in hospitality and tourism industries. J Hospitality Tourism Res 2005;29(3): 372-95.

Harrington RJ, Lemak DJ, Reed R, Kendall KW. A question of fit: the links among environment, strategy formulation, and performance. J Bus Manage 2004;10(1): 15-38.

Harris LC, Ogbonna E. Initiating strategic planning. J Bus Res 2006;59(1):100-11.

He ZL, Wong PK. Exploration vs. exploitation: an empirical test of the ambidexterity hypothesis. Org Sci 2004;15(4):481-94.

Hogarth RM. Cognitive processes and the assessment of subjective probability distributions. J Am Stat Assoc 1975;70(350):271-89.

Idenburg PJ. Four styles of strategy development. Long Range Plann 1993;26(6):132-7.

Miller CC, Cardinal LB. Strategic planning and firm performance: a synthesis of more than two decades of research. Acad Manage J 1994;37(6):1649-65.

Miller D, Friesen PH. Innovation in conservative and entrepreneurial firms: two models of strategic momentum. Strateg Manage J 1982;3(1):1-25.

Mintzberg H. Strategy making in three modes. Calif Manage Rev 1973;16(2):44-53.

Mintzberg H. Crafting strategy. Harvard Bus Rev 1987;65(4):66-73.

Mintzberg H. The design school: reconsidering the basic premises of strategic management. Strateg Manage J 1990;11(3):171-95.
Mintzberg H. The fall and rise of strategic planning. Harvard Bus Rev 1994;72(1):107.

Mintzberg H, Waters JA. Of strategies, deliberate and emergent. Strateg Manage J 1985;6(3):257.

Newman WH, Logan JP. Strategy, policy, and central management. Cincinnati, OH: South-Western Pub. Co.; 1981.

Noble $\mathrm{CH}$. The eclectic roots of strategy implementation research. J Bus Res 1999;45(2): 119-34.

Parnell JA. Strategic consistency versus flexibility: does strategic change really enhance performance? Am Bus Rev 1994;12(2):22-30.

Podsakoff PM, MacKenzie SB, Lee JY, Podsakoff NP. Common method biases in behavioral research: a critical review of the literature and recommended remedies. J Appl Psychol 2003;88(5):879-903.

Rudd JM, Greenley GE, Beatson AT, Lings IN. Strategic planning and performance: extending the debate. J Bus Res 2008;61(2):99-108.

Shepherd DA, Wiklund J. Are we comparing apples with apples or apples with oranges? Appropriateness of knowledge accumulation across growth studies. Entrep Theory and Pract 2009;33(1):105-23.

Shimizu K, Hitt MA. Strategic flexibility: organizational preparedness to reverse ineffective strategic decisions. Acad Manage Exec 2004;18(4):44-59.

Slevin DP, Covin JG. Strategy formation patterns, performance, and the significance of context. J Manage 1997;23(2):189.

Tuominen M, Rajala A, Möller K. How does adaptability drive firm innovativeness? J Bus Res 2004;57(5):495-506. 